\title{
Cianoacrilato. Definición y propiedades. Toxicidad y efectos secundarios. Aplicaciones en medicina y odontología
}

\section{Cyanoacrylate. Definition and properties. Toxicity and side effects. Applications in medicine and dentistry}

\author{
González González JM*
}

\section{RESUMEN}

Introducción: el cianoacrilato es un líquido incoloro con propiedades adhesivas. Se emplea habitualmente en trabajos de bricolaje. En medicina y odontología ha sido utilizado generalmente como sutura de piel.

Material y métodos: se hizo una revisión bibliográfica acerca del cianoacrilato y su uso en medicina y odontología.

Resultados: en diferentes tablas se recogen productos comerciales que contienen cianoacrilato, sus utilidades no médicas, los requisitos para uso médico, aplicaciones en medicina y odontología, y sus efectos nocivos. Discusión: Los cianoacrilatos de cadena corta (etil y metilcianoacrilato) no son aptos para uso médico, pues se degradan rápidamente dando productos tóxicos. Sin embargo se emplean de cadena larga (octil y butilcianoacrilato) que dan menos toxicidad. Se aconseja emplear en zonas superficiales y libres de tensión.

Palabras clave: Cianoacrilato, definición, propiedades, toxicidad, efectos secundarios, aplicaciones, medicina, odontología.

\section{SUMMARY}

Introduction: Cyanoacrylate is a colorless liquid with adhesive properties. It is commonly used in DIY work. In medicine and dentistry, it has been widely used as a skin suture.

Material and methods: A literature review was made of cyanoacrylate and its use in medicine and dentistry. Results: In different tables are commercial products containing cyanoacrylate, general utilities, requirements for medical use, medical and dental applications, and its harmful effects.

Discussion: The short-chain cyanoacrylates (ethyl and methylcyanoacrylate) are not suitable for medical use, because they degrade quickly giving toxic products. However long chain used (octyl and butylcyanoacrylate) to offer less toxicity. It is recommended for surface areas and tension free.

Key words: Cyanoacrylate, definition, properties, toxicity, side effects, applications, medicine, dentistry.

Fecha de recepción: Octubre de 2010.

Aceptado para publicación: Enero de 2011.

* Médico estomatólogo. Doctor en medicina y cirugía. Práctica privada en Salamanca.

González González JM. Cianoacrilato. Definición y propiedades. Toxicidad y efectos secundarios. Aplicaciones en medicina y odontología. Av. Odontoestomatol 2012; 28 (2): 95-102. 


\section{INTRODUCCIÓN}

\section{Definición y propiedades}

El cianoacrilato fue primeramente sintetizado por Airdis en 1949, aunque la descripción de sus propiedades adhesivas se debe al Dr. Harry Coover quien, en 1951, sintetizó el etil cianoacrilato, intuyendo entonces su posible uso como adhesivo quirúrgico.

Ha tenido distintas utilidades, pero sobre tejidos corporales su mayor aplicación ha sido para hacer suturas sin cirugía.

El cianoacrilato es generalmente una resina acrílica, que polimeriza rápidamente en presencia de agua formando cadenas largas y fuertes. Son líquidos incoloros y de baja viscosidad. El metil-2-cianoacrilato se usa como componente del pegamento de cianoacrilato y su calentamiento provoca la despolimerización, produciendo elementos gaseosos muy irritantes para los pulmones y los ojos.

El $n$-butil-cianoacrilato es un éter, insoluble en agua, incoloro y líquido. Su empleo principal es como componente de cianoacrilatos de uso médico.

La fuerza adhesiva de este compuesto depende de la polimerización de monómeros de cianoacrilato formándose uniones muy fuertes. Los ácidos débiles inhiben débilmente la polimerización, sin embargo los ácidos fuertes la paran completamente. La ruptura de este polímero puede hacerse con acetona (quitaesmalte de uñas, por ejemplo).

Cianoacrilato y algodón reaccionan porque el algodón está constituido primariamente de celulosa, la cual posee muchos grupos hidróxilos $\left(\mathrm{OH}^{-}\right)$, iniciándose una reacción de polimerización muy exotérmica.

El cianoacrilato puede ser sintetizado por reacción de formaldehído con alkyl cianoacrilato, obteniéndose así un prepolímero, el cual por calentamiento es despolimerizado en un líquido monómero. Dicho monómero puede ser modificado para obtener distintos compuestos de longitudes de cadena diferentes.

Algunos pegamentos son $100 \%$ etil cianoacrilato y otros tienen una mezcla en su composición.
En la aplicación sobre tejidos vivos, el monómero sufre una reacción de hidroxilación exotérmica que resulta en una polimerización del adhesivo.

\section{Aplicaciones}

Los primeros usos médicos del cianoacrilato lo fueron en soldados americanos durante la guerra de Vietnam en los años 60, empleado como sutura y como agente hemostático, para heridas con sangrado imparable (ejemplo: heridas de pecho). Se administraba en spray y resultaba muy efectivo para parar el sangrado.

El pegamento de cianoacrilato del comercio no es apto para uso médico, pues está hecho de una cadena corta de cianoacrilato (metil cianoacrilato o etil cianoacrilato), que no es compatible con el tejido humano, debido a que se degradan rápidamente y dan productos tóxicos que podrían empeorar la herida.

Para uso médico se emplean cianoacrilatos de cadena larga y el tipo de adhesivo depende de la parte del cuerpo donde se aplique.

En los años 1980 surgió la idea de distribuir medicinas a lugares específicos del cuerpo mediante nanoesferas o nanopartículas (1), que podrían contener drogas de liberación prolongada en el cuerpo (2). Estas esferas de cianoacrilato de cadena larga estarían rellenas de una droga activa o adsorbida en su superficie. De este modo se podrían distribuir péptidos, proteínas, vacunas o antiproteasas, administradas oral o intravenosamente. Esto tiene especial interés en el caso de los tumores, pues la droga causa efectos secundarios y solo debería llegar al tumor.

El cianoacrilato ha sido empleado para exponer las huellas dactilares (3), mediante vapor de etilcianoacrilato creando una capa donde se ven los bordes (4). Este proceder debe hacerse en un espacio encerrado, pues el oxígeno inhibe la polimerización. Este método también puede servir para mostrar otras secreciones exocrinas tales como sangre o sudor, pues no las estropea y permite usarlas en test de DNA.

En aplicaciones médicas y veterinarias se emplea el n-butil-cianoacrilato y el isobutil cianoacrilato. Son 
bacteriostáticos y no requieren de anestesia. Los ésteres butil dan uniones fuertes y rígidas, mientras que los esteres octal son uniones débiles y flexibles.

Respecto de las suturas, el butil-2-cianoacrilato se ha usado en cirugía plástica, por ejemplo en cierre de piel fácil o en blefaroplastia. Por el contrario, el octil 2 cianoacrilato es más fuerte y flexible, con lo que puede emplearse en incisiones más largas.

En su aplicación se aconseja que en el sitio de laceración la piel no esté a tensión y que no queden espacios muertos antes de sellar con el adhesivo.

\section{Toxicidad y efectos secundarios}

Como el cianoacrilato puede irritar la piel, la "U.S. Food and Drug Administration" no aprobó el uso médico civil del "superglue" hasta 1988, cuando se desarrolló la variante octil cianoacrilato.

El calentamiento del metil cianoacrilato causa despolimerización produciendo productos gaseosos fuertemente irritantes para los pulmones y los ojos.

Los derivados del cianoacrilato de cadena más corta tienen más grado de toxicidad para los tejidos que los de cadena larga.

Inyectado subcutáneamente el cianoacrilato produce inflamación, necrosis tisular y granulación, al causar toxicidad histológica debido a los productos de degradación como el formaldehído. Los componentes de cadena larga se degradan más lentamente produciéndose menos toxicidad al liberar esos productos más gradualmente.

Es aconsejado no usar en mucosa oral, manos, pies o en articulaciones, donde los movimientos repetitivos y el lavado pudieran causar la pérdida prematura del adhesivo. Tampoco se debería usar en heridas de úlceras de decúbito, y en mordidas humana o animal.

Situada sobre la herida actúa como una barrera para la epitelización, sin embargo también puede causar reacciones de cuerpo extraño e incrementar el riesgo de infección.
En un estudio con ratas inyectando subcutáneamente cuatro productos, agua destilada como control, éster cianoacrilato (Superbonder ${ }^{\circledR}$ ), n-butil-cianoacrilato (Histoacril ${ }^{\circledR}$ ) y alfa cianoacrilato (Three Bond $®$ ) dio irritación en todos los grupos, aunque disminuía con el paso del tiempo. El considerado con menos irritación y más biocompatible fue el alfa cianoacrilato (5).

El uso del n-butil-2-cianoacrilato aplicado en heridas de mucosa bucal no produce alteraciones significativas en el perfil de hígado o riñón, mientras que si da alteraciones significativas en el perfil bioquímico estudiado de nitrógeno y urea sanguínea, alanina amino transferasa, proteínas totales, bilirrubina total y amilasa (6).

Cuando el cianoacrilato es colocado profundamente en alvéolos postextracción o bajo colgajos puede provocar reacciones de cuerpo extraño $(7,8)$.

Para evitar la toxicidad, en odontología se han desarrollado diferentes formas de cianoacrilato como metil, etil, isobutil, isohexil y octil. El n-butil-2-cianoacrilato es comúnmente usado para cerrar heridas a baja tensión, aunque sus efectos sobre hígado y riñón no son conocidos. Sin embargo, un estudio en ratas de parámetros bioquímicos resultó no hallar diferencias significativas en nitrógeno y urea sanguínea, creatinina, alanina aminotransferasa, aspartato aminotransferasa, bilirrubina total, proteínas totales, albúmina y amilasa. De esto último se concluye que el n-butil-2-cianoacrilato es el adhesivo conveniente en cirugía oral (9).

Hay descrita la aparición de leucemia linfoblástica aguda en un paciente con exposición crónica de la mucosa oral a cianoacrilato (10).

En algunos casos se ha descrito ingestión accidental de cianoacrilato afectando a boca, faringe, laringe, esófago y resto de sistema gastrointestinal, sin indeseables secuelas debido a la pronta intervención (11).

En un estudio del efecto bioquímico, en hígado y riñón de ratas, del n-butil-2-cianoacrilato y del 2-octilcianoacrilato, aplicados sobre una incisión hecha en mucosa oral dio como resultado que el grupo tratado con n-butil-cianoacrilato no tuvo diferencias significativas respecto del grupo control, pero el 2-octil- 
cianoacrilato si produjo alteraciones en nitrógeno y urea en sangre, alanina aminotransferasa, proteínas totales, bilirrubina total y amilasa (6).

\section{MATERIAL Y MÉTODOS}

Para realizar el estudio se ha hecho recopilación de la información bibliográfica más reciente de la base de datos Medline, acerca del uso del cianoacrilato en diferentes ramas de la medicina y en especial en estomatología y odontología.

\section{RESULTADOS}

En la tabla 1 se recogen diferentes productos de cianoacrilato comercializados. Algunas utilidades para uso no médico se hallan en la tabla 2. La tabla

\section{TABLA 1.- PRODUCTOS COMERCIALES QUE CONTIENEN CIANOACRILATO}

\begin{tabular}{|l|l|l|}
\hline Metil y etil & $\begin{array}{l}\text { Octil } \\
\text { cianoacrilato }\end{array}$ & $\begin{array}{l}\text { n-butil- } \\
\text { cianoacrilato }\end{array}$ \\
\hline Superglue & Liquiband & Xoin \\
Krazy Glue & Surgiseal & Gesika \\
& Floraseal & Periacryl \\
& Dermabond & Glushield \\
& Nexaband & VetGlu \\
& & Vetbond \\
& & Liquivet \\
& & Indermil \\
& & Histoacryl \\
& & Tissue-Glu \\
& & Liquid Bondage \\
\hline
\end{tabular}

TABLA 2.- ALGUNAS UTILIDADES DEL CIANOACRILATO EN USO NO MÉDICO

- Ensamblar prototipos electrónicos.

- Unir piezas de aeromodelos.

- Retenciones de nudos y cinturones.

- Trabajos de bricolage.

- Trabajos en acuarios marinos.
3 recoge los requisitos que se estiman necesarios para que el cianoacrilato pueda ser empleado en medicina. Los usos médicos y odontológicos se hallan en las tablas 4 y 5 respectivamente. Y los efectos nocivos de su empleo en la tabla 6.

\section{TABLA 3.- REQUISITOS DE UN CIANOACRILATO PARA USO MÉDICO}

- Biocompatible.

- No tóxico para los tejidos.

- Bacteriostático. La remoción de la sutura para cerrar herida produciría bacteriemia. En este caso no.

- Hemostático.

- Fácil manejo. No necesita de una segunda sesión para ser removido.

\section{TABLA 4.- USO MÉDICO DEL CIANOACRILATO}

- Suturas de cirugía y laceraciones de piel $(12,13)$.

- Agente hemostático en sangrado de estructuras vasculares, como malformaciones arteriovenosas, aplicándolo mediante angiografía (14).

- Adhesivo oftálmico $(15,16)$ y como sutura en blefaroplastia.

- Úlceras de estómago.

- Lesiones de pulmón.

- Reducir cicatrices.

- En aplicación de parche de pericardio para tratamiento quirúrgico de ventrículo izquierdo (17).

- Nanopartículas o nanoesferas con medicamento en su interior $(1,2)$.

- Para exponer huellas dactilares u otras secreciones $(3,4)$.

- En el tratamiento del sangrado de varices gástricas (18), varices esofágicas (19), varices duodenales (20), varices del colón (21).

- Para estabilizar cartílagos en otorrinolaringología (22).

- En cirugía de cataratas $(23,24)$.

- En cierre de fístula bronco-esofágica (25).

- En escleroterapia de hemorragias gastrointestinales y varices esofágicas $(19,26)$. 


\section{TABLA 5.- USO ODONTOLÓGICO DEL CIANOACRILATO}

- Sellar alvéolos postextracción.

- Adhesión de injertos libres de mucosa.

- Protección pulpar directa.

- Apósito protector en gingivectomía.

- En cirugía menor.

- Úlceras.

- Fijación de colgajos mucoperiósticos.

- Para suturar.

- Como material de relleno a retro y en cirugía endodóntica (5).

- Como uso incorrecto de pegar prótesis bucales rotas (27)

Reparación de diente fracturado (28).

- Adhesión de brackets (29).

- Adhesivo de fracturas dentales (30).

\section{TABLA 6.- EFECTOS NOCIVOS DEL CIANOACRILATO}

- El calentamiento del metil cianoacrilato da gases tóxicos para el pulmón y los ojos.

- Inyectado subcutáneamente produce inflamación, necrosis tisular y granulación.

- Puede producir reacciones de cuerpo extraño colocado en alvéolos postextracción $(7,8)$.

- Puede incrementar el riesgo de infecciones

- Alteraciones significativas del perfil bioquímico (urea, alanin aminotransferasa, proteínas totales, bilirrubina total y amilasa) (6).

- Descrita leucemia linfoblástica aguda en un paciente con exposición crónica de la mucosa oral a cianoacrilato (10).

\section{DISCUSIÓN}

El uso de cianoacrilato como material adhesivo sin sutura tiene muchas ventajas, aunque la mayoría de estudios indican que debería ser restringido a aplicación superficial. Son conocidas sus propiedades bacteriostáticas para muchos tipos de bacterias, así como sus propiedades hemostáticas. El cia- noacrilato debería servir de manera aceptable en casos de recubrimiento pulpar, aunque se siga empleando el hidróxido cálcico como material de elección (7).

Como adhesivo de tejidos en cirugía podría simplificar el procedimiento quirúrgico, estabilizando las superficies a través de la homeostasis, el sellado de heridas y la fijación del tejido en áreas inaccesibles para suturar.

El uso de n-butil-cianoacrilato frente a suturas de seda, en cierre de colgajos mediante cirugía, resultó en menos inflamación durante el curado de la primera semana, sin embargo entre 21 días a 6 semanas la forma de curación era similar con ambos tipos de materiales (31).

Estudios en conejos de reparaciones, de perforaciones de membrana sinusal de $1.5 \mathrm{~cm}$ de diámetro, hechas con cianoacrilato sobre uno solo de los lados resultó en la reparación de la membrana mediante epitelio continuo (32).

Cuando se compara el cianoacrilato con el uso de sutura tradicional en el cierre de heridas, en zonas libres de tracción, se vio que el cianoacrilato es más eficaz, con un tiempo de cierre menor y más estético (33). Entre sus ventajas se ha señalado además que no requiere esterilización ni aplicadores especiales, debido a que es una sustancia inerte (34).

La creación de nanoesferas o nanopartículas de cianoacrilato con drogas en su interior es una esperanzadora vía abierta en el tratamiento específico de tumores $(1,2)$.

En algunos casos se ha empleado el cianoacrilato para aislamiento con el dique de goma pegándolo en mucosa vestibular, aunque se empleó superglue ${ }^{\circledR}$ de Loctite (35), elemento este que creemos no es apropiado para uso médico por estar compuesto de metil y etil cianoacrilato. Es necesario tener en cuenta que los cianoacrilatos de cadena corta son considerados tóxicos para el tejido. Los de cadena media (butil-cianoacrilato) son ampliamente empleados en Europa y Canadá. Los más nuevos, los cianoacrilatos de cadena larga (octil-2-cianoacrilato) tienen una amplia aceptación en procedimientos médicos, es- 
pecialmente en medicina cutánea en laceraciones e incisiones.

En un estudio de adhesión de bracket con cianoacrilato frente a resina compuesta dio fallos del bracket del 55,6\% cuando se empleó cianoacrilato frente al $11,3 \%$ de las uniones con resina compuesta, sin embargo la decalcificación del esmalte fue similar con ambos productos durante un año de tratamiento ortodóncico. Estos resultados desaconsejan el cianoacrilato como material de adhesión (29).

\section{CONCLUSIONES}

Del estudio bibliográfico efectuado podemos concluir que:

1. Los cianoacrilatos de cadena corta (etil y metilcianocarilato) no son aptos para uso médico debido a que se degradan rápidamente con emisión de productos tóxicos.

2. Los cianoacrilatos de cadena larga (octil y butilcianoacrilato) se emplean ampliamente en medicina en diferentes especialidades. Se degradan más lentamente y genera menos toxicidad.

a) Se aconseja únicamente su uso de modo superficial, pues subcutáneamente puede dar reacción de cuerpo extraño.

b) Como elemento de sutura ha de emplearse en zonas libres de tensión y sin movilidad.

c) En odontología puede tener también su utilidad como adhesivo en multitud de procedimientos, como ha quedado recogido a lo largo de este texto.

\section{BIBLIOGRAFÍA}

1. Vauthier C. et al. Poly (alkylcyanoacrylates) as biodegradable materials for biomedical applications. Adv Drug Delivery Rev. 2003;55:519-48.

2. Fresta M, Cavallaro G, Giammona G, Wehri E, Puglidsi G. Preparation and characterization of polyethyl-2-cyanoacrylate nanocapsules containing antiepileptic drugs. Biomaterial. 1996;17:751-8.
3. Lewis L et al. Processes involved in the development of latent fingerprints using the cyanoacrylate fuming method. J Forensic Sci. 2001;46:241-6.

4. Wargacki SP et al. Enhancing the quality of aged latent fingerprints developed by superglue fuming; loss and replenishment of initiator. J Forensic Sci. 2008;53:1138-44.

5. Moretti Neto RT, Mello I, Moretti AB, Robazza CR, Pereira AA. In vivo quantitative analysis of the biocompatibility of different cyanoacrylate-based adhesives. J Can Dent Assoc. 1990;56(4):331-4.

6. Lopez-Jornet P, Camacho-Alonso F, GomezGarcia F. Evolution of biochemical the two cyanoacrylates: an experimental study in rats. Journal of biomaterials applications. 2009;24 (3):197-207.

7. Herod EL. Cyanoacrylates in dentistry: a review of the literature. J Can Dent Assoc. 1990;56(4): 331-4.

8. Forseth M, O'Grady K, Toriumi DM. The current status of cyanoacrylates and fibrin tissue adhesives. J Long Term Eff Med Implants. 1992;2(4):22133.

9. Inal S, Yilmaz N, Nisbet C, Güvenc T. Biochemical and histopathological finding of N-butyl-2cyanoacrylate in oral surgery: an experimental study. Oral Surg Oral Med Oral Pathol Oral Radiol Endod. 2006;102(6):14-7.

10. Layden BT, Joseph M, Tallman MS, Platanias LC. Acute lymphoblastic leukaemia in a patient with chronic cyanoacrilate exposure. Acta Haemaphol. 2007;118(4):242-3.

11. Yilmaz T, Yilmaz G. Accidental cyanoacrylate glue ingestion. Int J Pediatr Otorhinolaryngol. 2005; 69(6):853-5.

12. Man ML et al. Cost consequence analysis comparing 2-octyl cyanoacrylate tissue adhesive and suture for closure of simple lacerations: a randomized controlled trial. Annals of Emergency Medicine. 2009;53:189-97. 
13. Cooper JM, Paige KT. Primary and revision cleft lip repairs using octyl-2-cyanoacrylate. J Craniofac Surg. 2006;17(2):340-3.

14. Lee BB, Do YS, Yakes W, Kim DI, Mattassi R, Hyon WS. Management of arteriovenous malformations: a multidisciplinary approach. J Vasc Surg. 2004;39(3): 590-600.

15. Oelker AM et al. Ophthalmic adhesives: a materials chemistry perspective. J Mater Chem. 2008;18:2509-616.

16. Díaz-Valle D, Benítez Del Castillo Sánchez JM, Díaz Rodríguez E, Toledano Fernández N, Arteaga Sánchez A, Sayagues Gómez, O. Manejo de la queratopatia neurotrófica mediante tarsorrafia con cianoacrilato y suero autólogo. Arch Soc Esp Oftalmol. 2003;78:2.

17. Mokiya T, Ishii O, Yamazaki. Surgical treatment for subacute left ventricular free wall rupture complicating acute myocardial infractionpericardial patch gluing method. Nippon Kiobu Geka Gakkai Zassahi. 1996;44:896-910.

18. Ferguson JW, Tripathi D, Hayes PC. Review article: the management of acute variceal bleeding. Aliment Pharmacol Ther. 2003;18(3): 253-62.

19. D'Imperio N, Piemontese A, Baroncini D et al. Evaluation of undiluted n-butyl-2-cyanoacrylate in the endoscopic treatment of upper gastrointestinal tract varices. Endoscopy 1996;28(2):239-43.

20. Ota K, Shirai Z, Masuzaki T et al. Endoscopic injection sclerotherapy with n-butyl-2-cyanoacylate for ruptured duodenal varices. J Gastroenterol. 1998:33(4):550-5.

21. Chen WC, Hou MC, Lin HC, Chang FY, Lee SD. An endoscopic injection with $\mathrm{N}$-butyl-2cyanoacrylate used for colonic variceal bleeding: a case report and review of the literature. Am J Gastroenterol. 2000;95(2):540-2.

22. Galil K, Schofield I, Wright G. Scientific effect of $\mathrm{N}$-butyl-2-cyanoacrylate (histoacryl Blue) on the healing of skin wounds. J Can Dental Assoc. 1984;50:565-9.

23. Alio JL, Mullet ME, Garcia JC. Use of cyanoacrylate tissue adhesive in small incision cataract surgery. Ophthal Surg Lasers. 1996;27:270-4.

24. Bodaghi, Levy C, Votan P, Hoang Wuan T. Value of cyanoacrylate tissue adhesives in peripheral corneal ulcers of inflammatory origin. J Fr Ophthalmol. 1996;19:2-32.

25. Jones C, Laurence BH, Faulker KW, Culling GL. Clousure of a benign bronchoesophageal fistula by endoscopic injection of bovine collagen, cyanoacrylate glue and gel foam. Aust N Z J Surg. 1996;66:53-5.

26. Jutaba R, Jensen M. Management of upper gastrointestinal bleeding in the patient with chronic liver disease. Med Clin North Am. 1996;80:1035-68.

27. Winkier S, Wood R, Facchiano AM, Boberick KG, Patel AR. Prosthodontic self-treatment with acrylic resin superglue: a case report. J Oral Implantol. 2006;32(3):132-6.

28. Hile LM, Linklater DR. Use of 2-octyl-cyanoacrylate for the repair of a fractured molar tooth. Ann Emerg Med. 2006;47(5):424-6.

29. Le PT, Weinstein M, Borislow AJ, Braitman LE Bond failure and decalcification: a comparison of a cyanoacrylate and a composite resin bonding system in vivo. Am J Orthod Dentofacial Orthop. 2003;123(6):624-7.

30. Chappelow CC, Byerly TJ, Inzino CS, Millich F, Eick JD. Design and development of isocyanoacrylates as dental adhesives. J. Dental Res. 1996;75:761-7.

31. Kulkarni S, Dodwad V, Chava V. Healing of periodontal flags when closed with silk sutures and $\mathrm{N}$ butyl-cyanoacrylate: a clinical and histological study. Indian J Dent Res. 2007;18(2):72-7.

32. Choi BH, Kim BY, Huh JY, Lee SH, Zhu SJ, Jung $\mathrm{JH}$ et al. Cyanoacrylate adhesive for 
closing sinus membrane perforations during sinus lifts. J Craniomaxillofac Surg. 2006;34(8): 505-9.

33. Orozco-Razón LF, Millán-Guerrero RO, Vera-Rodríguez SE. Cianoacrilato comparado con cirugía tradicional en el cierre de heridas en zonas libres de tensión. Gac Med Mex. 2002;138(6): 505-9.

34. Quinn, Wells G, Sut Cliffe T. A randomized trial comparing octyl cyanoacrylate tissue adhesive and sutures in the management of laceration. JAMA. 1997;277:1527.

35. Cueto Suárez M. Aislamiento absoluto o como colocar el dique para cementar unas carillas cerámicas. Maxillaris. 2009; septiembre: 103-6.

\section{CORRESPONDENCIA}

Jesús M. González González

Ávila, $4,1^{\circ} \mathrm{A}$

37004 Salamanca 